\title{
Developing a novel manufacturing method to produce stiffened plate structures
}

\author{
Andrew J. H. Garrick ${ }^{1}$ (D) - Athanasios I. Toumpis ${ }^{1} \cdot$ Alexander M. Galloway $^{1}$ \\ Received: 13 September 2020 / Accepted: 15 December 2020 / Published online: 8 January 2021 \\ (C) The Author(s) 2021
}

\begin{abstract}
Isogrid is a highly efficient stiffened plate structure which was developed in the aerospace industry for use in rocketry and space structures. Its current form is unviable outwith these applications, as the available production methods are expensive due to excessive machining time in addition to considerable material wastage. The method detailed in this body of work was developed to manufacture Isogrid in a more efficient manner, so that its weight-saving properties may become more widely accessible. This novel Isogrid manufacturing process uses a rolling mill with patterned rollers to imprint a 3D structure of ribs into the surface of a billet material. To validate this method, a patterned roller was designed, manufactured and fitted to a rolling mill to produce sheets of aluminium AA1050 Isogrid. This process successfully created Isogrid in a sustainable, rapid manner. The samples produced were tested in 3-point bending and compared against flat plate of the same material. They were found to be $100 \%$ stronger in bending compared to a neutral flat plate with a strength shape factor of 1.6 after discounting the effect of cold work.
\end{abstract}

Keywords Isogrid $\cdot$ Forming $\cdot$ Rolling $\cdot$ Lightweight structures

\section{Introduction}

Lightweight structural materials are a focus of international research for their high strength to mass efficiency [1]. A key benefit is the reduction in the consumption of raw materials and fuel in the automotive, aviation, transport and construction industries $[1,2]$. Much of the available literature is focused on the improvement of mechanical properties in lightweight structures by investigation into composition and shape to develop materials which are both strong and light [3-5]. An example is structural steelwork which has been optimised to reduce mass using well-designed beam profiles such as the conventional I-beam geometry [6]. Such profiles allow the

Andrew J. H. Garrick

Andrew.garrick@strath.ac.uk

Athanasios I. Toumpis

Athanasios.toumpis@strath.ac.uk

Alexander M. Galloway

Alex.galloway@strath.ac.uk

1 Department of Mechanical \& Aerospace Engineering, University of Strathclyde, James Weir Building, 75 Montrose Street, Glasgow G1 1XJ, UK retention of mechanical properties despite becoming relatively lighter, by optimising the mass distribution of a structure to resist loading more efficiently [7]. The resultant strength to mass improvement can be described using a shape factor which is the ratio of the strength of a structure, to the strength of a neutrally shaped structure of the same mass [6].

Isogrid was developed as a lightweight plate structure for the American National Aeronautics and Space Administration (NASA) to capture the benefits of shape factor [8, 9]. Isogrid is a skin and rib structure composed of a network of stiffening elements connected to a thin plate. These ribs lend their strength to the skin by creating a hybrid lattice-membrane material which is particularly resistant to flexural out-ofplane loading [10]. Unlike many of its contemporary skin and rib variants in which stiffening elements were welded onto plate or joined with bolts, Isogrid was created as a single piece without joints [11]. This led to NASA adopting the term "integrally stiffened structure" as a common description for Isogrid and other rib-stiffened plates [12-14].

The appearance of Isogrid is distinct due to the pattern of equilateral triangles created by its 3 rib directions offset at $60^{\circ}$ to each other [10]. This geometry creates a quasi-isotropic mechanical behaviour when elastically loaded which allows its mechanical properties to be analysed and expressed as an equivalent thickness plate. This quasi-isotropic nature gave 
Isogrid its name as it is an "isotropic-grid" [10]. This behaviour does not extend fully into the plastic region, as anisotropic behaviour has been reported in the failure modes of Isogrid [15].

Different expressions for plates of equivalent thicknesses can be derived, which represent the various properties of Isogrid (such as mass, bending strength, stiffness and tensile strength). These are a function of geometric parameters such as rib height, rib width, skin thickness and rib volume fraction [10]. In order to find the "equivalent strength" thickness of Isogrid plate, an analytical method was used in which the impact of each stiffening member was averaged out across the plate $[10,17]$. To find the plate thickness of equivalent mass, these geometric parameters must be used to evaluate the volume of the structure, which is divided by its base area to return the height of an equivalent mass plate. It can therefore be argued that the mass efficiency/shape factor of Isogrid in bending can be expressed as a function of the difference in thickness of these equivalent plates.

In the Isogrid design handbook generated by McDonnel Douglas for NASA [10], it was claimed that the stiffness of a plate could be increased by a factor of 195 by doubling its mass in the form of ribs; however, such Isogrid geometry is difficult to manufacture in an efficient manner, making Isogrid an expensive material. In metals, it is standard to begin with a thick piece of stock material and mill out triangular pockets to leave the skin and rib structure (see Fig. 1). The flat Isogrid plates are then formed to whatever shape is desired using a press brake or similar forming process $[10,18]$. This method creates highly customised Isogrid geometries but is time consuming and wastes up to $90 \%$ of the base material $[10,11]$.

The above manufacturing method has undergone significant research and improvement over the last 50 years. Other manufacturing methods have been developed to produce Isogrid [19]; however, they are all still batch processes with

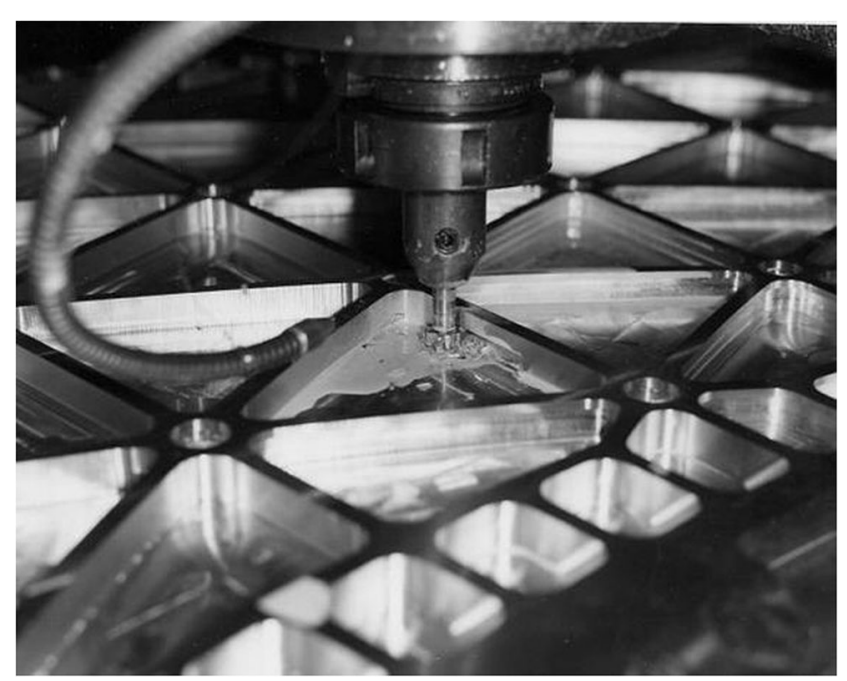

Fig. 1 Isogrid being CNC milled from a solid block of material [16] associated high costs in labour, machine time, equipment and waste material $[12,19]$. Such processes allow a high level of customisation of the product which is accompanied by a high price point. This is particularly well suited to cost-insensitive, high-end applications which require custom sheets, with high mass efficiencies and low production quantities, but it is inaccessible to other industries. NASA evaluated the cost of a stiffened 6-m long, 4.8-m diameter cylinder for spacecraft to be $\$ 1.5$ million [20].

The tooling in any forming process must exert enough force onto the stock to reach the material's flow stress [21, 22]. In the direct forming of a part using a die press, the entire part is formed at once; therefore, the force required to form the part is equal to the flow stress times the area of contact during forming [23]. Using a roller only requires flow stress to be achieved along one concentrated contact strip where the roller meets the billet $[24,25]$. This requires less force and energy than directly stamping the pattern into a billet, as it forms the target geometry incrementally, rather than all at once.

As an alternative to these costly methods, the current study explores a novel manufacturing process that forms Isogrid from plain metal billets using an adapted rolling mill. This body of work demonstrates that Isogrid can be produced in a rolling process compatible with current metal rolling practices by designing a prototype system and experimentally rolling Isogrid. The design methodology for the roller is detailed, and the final design output, evidence of process success and improvement in specimen bending stiffness are reported. Created in this manner, Isogrid could be more accessible for wider industry usage, allowing the improvement of fuel efficiency by reducing the weight of vehicles, aircraft and shipping containers.

\section{Process design and implementation}

A Durston D4 158 rolling mill was modified with a prototypepatterned roller that was designed and manufactured with the addition of grooves to imprint the desired target geometry. To design the grooves, a target Isogrid geometry was established, then wrapped around a cylindrical roller and subtracted using Solidworks.

It was assumed that the billet would deform into the grooves on the roller to create the target geometry. This implies that the billet will be progressively formed between the points of entry and exit in the roll gap. There will be some elastic recovery from the residual elastic stress in the billet and the roller will elastically deform during the process; however, this is an issue of tolerance [26]. The between-support length of the patterned roller was small enough that varying the radius over its length to account for bending (crowning the roller) was not necessary. Crowning or similar techniques should be considered to ensure dimensional tolerancing at an 
industrial scale. The design process to establish the target geometry, and thus, the roller geometry was as follows:

The ribbed side of the Isogrid structure must contain 3 directions of ribs, each at $60^{\circ}$ to one another in order to achieve quasi-isotropic mechanical properties [10]: correspondingly, the face of the roller contained 3 directions of grooves, each at a helix angle of $60^{\circ}$ to the others. One groove was aligned with the roll direction $\left(0^{\circ}\right)$ to minimise variation in forces over a revolution of the roller. The pattern could be rotated on the cylindrical surface; however, if a groove were to be aligned longitudinally along the roller (perpendicular to the roll direction), the roller would experience a periodic change in forces as the groove engaged and disengaged.

The original Durston roller was $60 \mathrm{~mm}$ diameter $\times 158 \mathrm{~mm}$ long on the roll face. The roller radius is linked to dimensions $a$ and $b$ (Fig. 2) as the pattern over the roller face must be continuous, so that multiple revolutions of the roller can be made without introducing discontinuities to the rolled pattern. The locations of the pattern nodes are where all three rib directions intersect, and an equal spacing of 12 helical grooves around the 60-mm diameter roller gave a node spacing of $a=$ $15.7 \mathrm{~mm}$, and cell height of $b=13.6 \mathrm{~mm}$ (Fig. 2).

The cross-section of the grooves was defined by the parameters $c$ and $h$ (Fig. 2), the base width and maximum height of each rib. This part of the design process used the volume relation below, to define a groove geometry which can accommodate the equivalent volume of a 0.5 -mm-thick plate when $90 \%$ full.

Based on a single equilateral triangular unit cell (Fig. 2), the following equation is derived:

$$
\begin{aligned}
\text { Volume }_{\text {isogrid }}= & \text { Volume }_{\text {skin }} \\
& + \text { Volume }_{\text {ribs }}-\text { Volume }_{\text {intersection }} \\
V(a, b, c, d, h, t,)= & \frac{\sqrt{3}}{4} a^{2} t \\
& +\frac{3}{2} a h\left(\frac{c+d}{2}\right)-6 h c\left(\frac{c+d}{2}\right)
\end{aligned}
$$

$$
\begin{aligned}
& \text { Equivalent mass thickness }(\mathrm{mm})=\bar{d}=\frac{\text { Volume }_{\text {isogrid }}}{\text { Area }_{\text {skin }}} \\
& =\frac{V(a, b, c, d, h, t,)}{\frac{\sqrt{3}}{4} a^{2}}
\end{aligned}
$$

A draft angle of $30^{\circ}$ was added to this profile to facilitate the egress of the formed Isogrid from the roller, as each rib must mesh and unmesh with the roller during forming as though it were part of a rack and pinion gear pair. The draft angle chosen was $30^{\circ}$ after examining an involute curve which was generated for a circle of radius $30 \mathrm{~mm}$. The shallow nature of these grooves with respect to the full radius of the roller meant that the involute curve was approximately linear over the depth of the groove. A straight-line approximation of this curve was tested against potential values of $c$ and $h$ in Solidworks and $30^{\circ}$ was found to have no interference as the rib and groove profile moved relative to each other. Considering both the volume relation and draft angle, suitable values of $c$ and $h$ were found to be $3 \mathrm{~mm}$ and $1.5 \mathrm{~mm}$ respectively.

The roller shown in Figs. 3 and 4 was manufactured and mounted into the Durston mill (Fig. 5). The material chosen for the roller was AISI4140 steel, which is equivalent to EN19. The roller hardness was measured to be $270 \mathrm{Hv}$ as received. No lubrication was added to the rollers.

Aluminium AA1050-O was chosen as the billet material due to its excellent formability and ductility. The AA1050 arrived in the -H14 state (half roll-hardened) and its hardness was measured to be $40 \mathrm{Hv}$. It was then annealed for an hour at $535{ }^{\circ} \mathrm{C}$ to the $-\mathrm{O}$ condition for rolling, at which point the hardness was measured to be $21 \mathrm{Hv}$.

Samples of Isogrid were successfully rolled from $3 \mathrm{~mm}$ aluminium AA1050-O sheet as seen in Figs. 7, 8 and 9. The rolled sheets were initially $110 \times 110 \times 3 \mathrm{~mm}$. The roll gap was set to $0.75 \mathrm{~mm}$ ( $25 \%$ of original thickness) using a feeler gauge which was accurate to $\pm 0.05 \mathrm{~mm}$. During the rolling process, this gap expanded and settled at $1.3 \mathrm{~mm}(43.33 \%$ of original thickness).
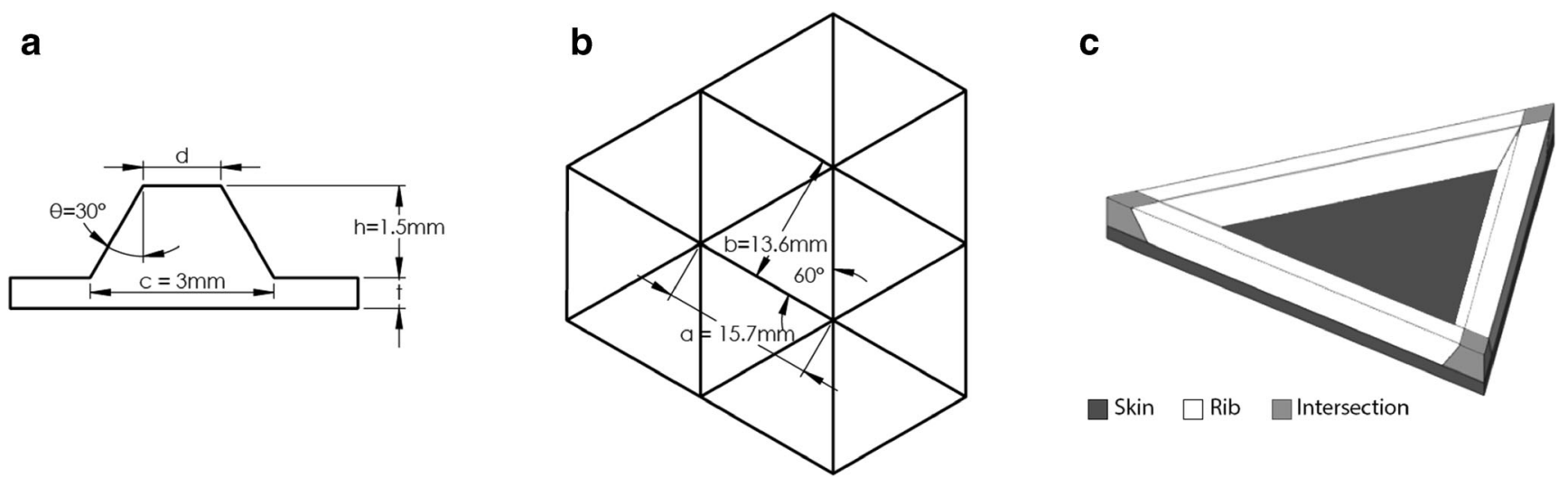

Fig. 2 a The target rib profile. b The target rib spacings. c Segments used in the calculation of the Isogrid volume 


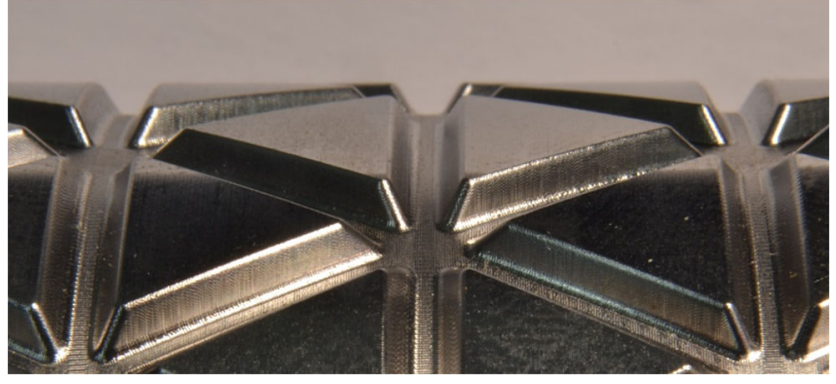

Fig. 3 Close up of the roller showing rib profile; the rib in the centre is in the $0^{\circ}$ direction

Each sample was measured individually by calliper to account for any differences between them. Three measurements of rib height and skin thickness were taken at varying points along the length of each sample in each group of 5. The average of these 15 measurements was taken to generate a value for $h$ and $t$ which were substituted into Eq. 1.3 to find the mass equivalent plate thickness for the group. The overall average dimensions of the rolled Isogrid were $t=1.44 \mathrm{~mm}$ (skin thickness) and $h=1.02 \mathrm{~mm}$ (rib height), total height $=2.46 \mathrm{~mm}$. The average rib width was calculated as $2.41 \mathrm{~mm}$ using these dimensions. The billet material extended by $58 \%$ on average, from $110 \mathrm{~mm}$ long to $176 \mathrm{~mm}$ as can be seen in Fig. 7, and reduced in thickness (of the skin) by $52 \%$ on average. This was a ratio of 7:5, skin thickness to rib height, or the ribs make up $41.4 \%$ of the overall height. The width of each billet increased from 110 to $111 \mathrm{~mm}$, which is an increase of $0.9 \%$. Using the equivalent mass thickness calculation (Eq. 1.3), the equivalent thickness plate of the rolled samples was $1.89 \mathrm{~mm}$. This is a 37\% reduction in mass from the original $3 \mathrm{~mm}$ plate.

Bend testing was performed to quantify the improvement in bending strength of the rolled samples. Plain strips of AA1050-O and AA1050-H14, and strips of rolled Isogrid in the as-rolled state and annealed state were tested to explore this relationship. Samples were sectioned using cooled abrasive disks into strips and finished with sandpaper. The test chosen was the full-U, support and former, three-point bend

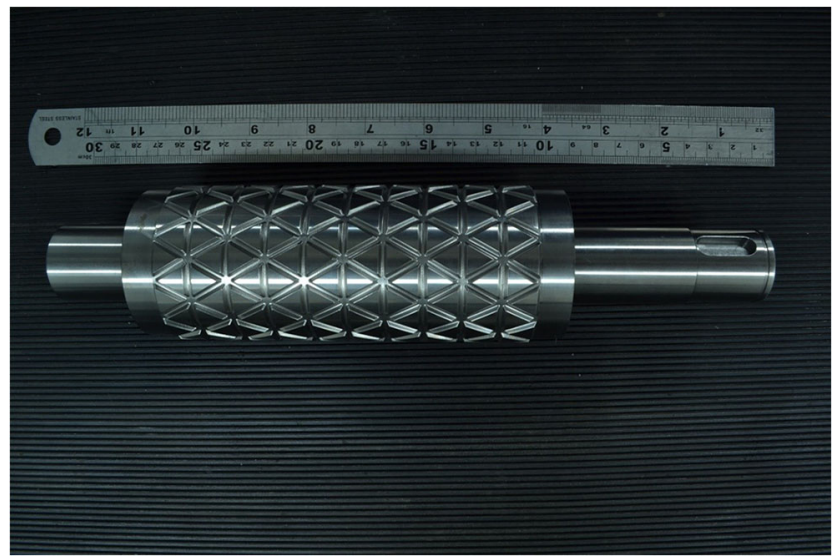

Fig. 4 Custom roller as received

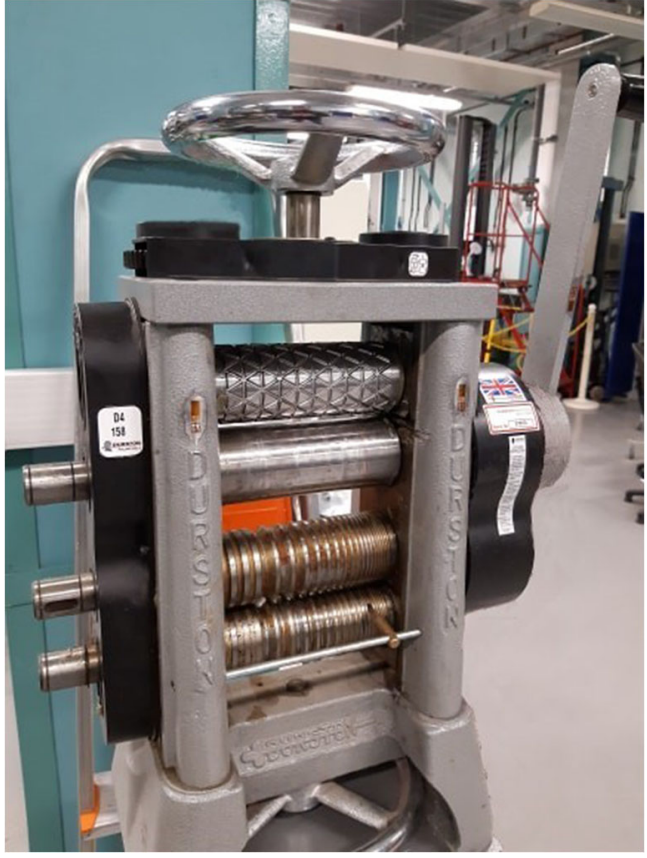

Fig. 5 The Durston mill with modified roller

test (Fig. 6) as described in international standards [27]. The full stiffening effect of Isogrid ribs is best represented in large samples, in which the applied forces can be distributed over a full network of ribs. Hence, the strips were cut to the width of two unit cells of the Isogrid pattern $(34 \pm 1 \mathrm{~mm})$. The distance, $L$, between the formers was set to $18 \mathrm{~mm}$ as per the standard for samples of this thickness [27]. The test was repeated 5 times for each sample group.

The sample dimensions, $b$ (width) and $d$ (height), were used to establish the bending stress of each individual sample from the measured data using the following equation:

$\frac{M}{I}=\frac{\sigma}{Y}=\frac{E}{R} \Rightarrow \sigma=\frac{M Y}{I}$

The bending stress values were then divided by the mass per square meter to compare these values as "specific bending strength." This accounted for the difference in mass as the Isogrid samples were significantly lighter than the plate samples due to extension in the rolling process. This produced the following relation which was used to find the specific bending strength of the samples from the experimental data:

$\sigma=\frac{M Y}{I} \times \frac{\bar{d}}{\rho}$

where

$M=\frac{F}{2} \times \frac{l}{2}$ 
Fig. 6 Diagram of bend test set up [27]

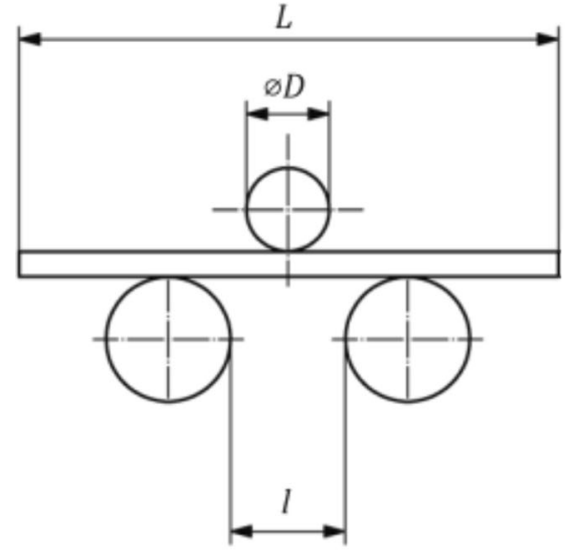

$Y=\frac{d}{2}$

$I=\frac{b d^{3}}{12}$

$F$ is the force measured by the load cell, $l$ is the distance between supports, and $b$ and $d$ are the width and thickness of the test samples respectively. As Isogrid does not have a constant thickness, $d$, a conversion factor developed in The Isogrid Design Handbook [10] was used to calculate its second moment of area. This expression uses non-dimensional geometric parameters from the rib structure to modify the second moment of area of the Isogrid skin section (equations from [10]):

$I=\frac{b d^{3}}{12} \times \frac{\beta^{2}}{1+\alpha}$

Where the following non-dimensional factors are defined as:

$\alpha=\frac{(\text { average }) \text { rib width } \times \text { rib height }}{\text { skin thickness } \times \text { skin height }}$

$\delta=\frac{\text { rib height }}{\text { skin thickness }}$

$\beta=\sqrt{3 \alpha(1+\delta)^{2}+(1+\alpha)(1+\alpha \delta)^{2}}$

Using these equations, the following values were calculated:

$\alpha=0.1255, \delta=0.7083, \beta=1.515$

Therefore, the conversion factor in (2.5) was calculated to be:

$$
\frac{\beta^{2}}{1+\alpha}=2.04
$$

\section{Results and discussion}

As the sample plates were manufactured in the mill, there were several phenomena which occurred, and qualitative observations were made on the surface properties of the resultant Isogrid. The process appears sensitive to the alignment of the billet as it enters the roll gap as there was a tendency for the samples to become parallelogrammical, with either the left- or right-hand side leading the other. There was a degree of minor curvature as the billet passed through the gap (Figs. 7 and 8), which was as expected, due to the frictional and geometric asymmetry of the rollers [28]. To remove any impact this had on bend testing, the samples were cut transverse to the curve; however, a number of post-production flattening methods can be employed to reduce this in an industrial context.

As seen in Fig. 9, the ribs had different qualities dependent on their direction. The $0^{\circ}$ ribs (roll direction) were rounded and reduced in height in comparison to the $\pm 60^{\circ}$ ribs which were taller and had flatter tops with sharper corners (Fig. 9). The difference in height between the rib directions can also be inferred by the texture of their surfaces: the $\pm 60^{\circ}$ ribs had fully filled the groove resulting in a smooth surface, whereas the $0^{\circ}$ ribs were dimpled as they had not filled the groove. This can be explained as the $0^{\circ}$ ribs were following the roll direction, and thus could elongate preferentially over extruding into the roller's groove. By contrast, the $\pm 60^{\circ}$ ribs were held captive by the roller during the process, forcing the material to flow further up into the grooves.

On the reverse side of the plate, the position of the ribs can be seen by shallow recesses which formed along the rib directions (Fig. 7b). These recesses are very similar to "extrusion defects" as described by Sabroff [23]. There were also high points located approximately midway between nodes on the \pm $60^{\circ}$ ribs (Fig. 9), and rounded edges near the nodes on these same ribs (Fig. 9). These issues are artefacts of material flow during the forming process and indicate that the groove geometry may need further optimisation to reduce 


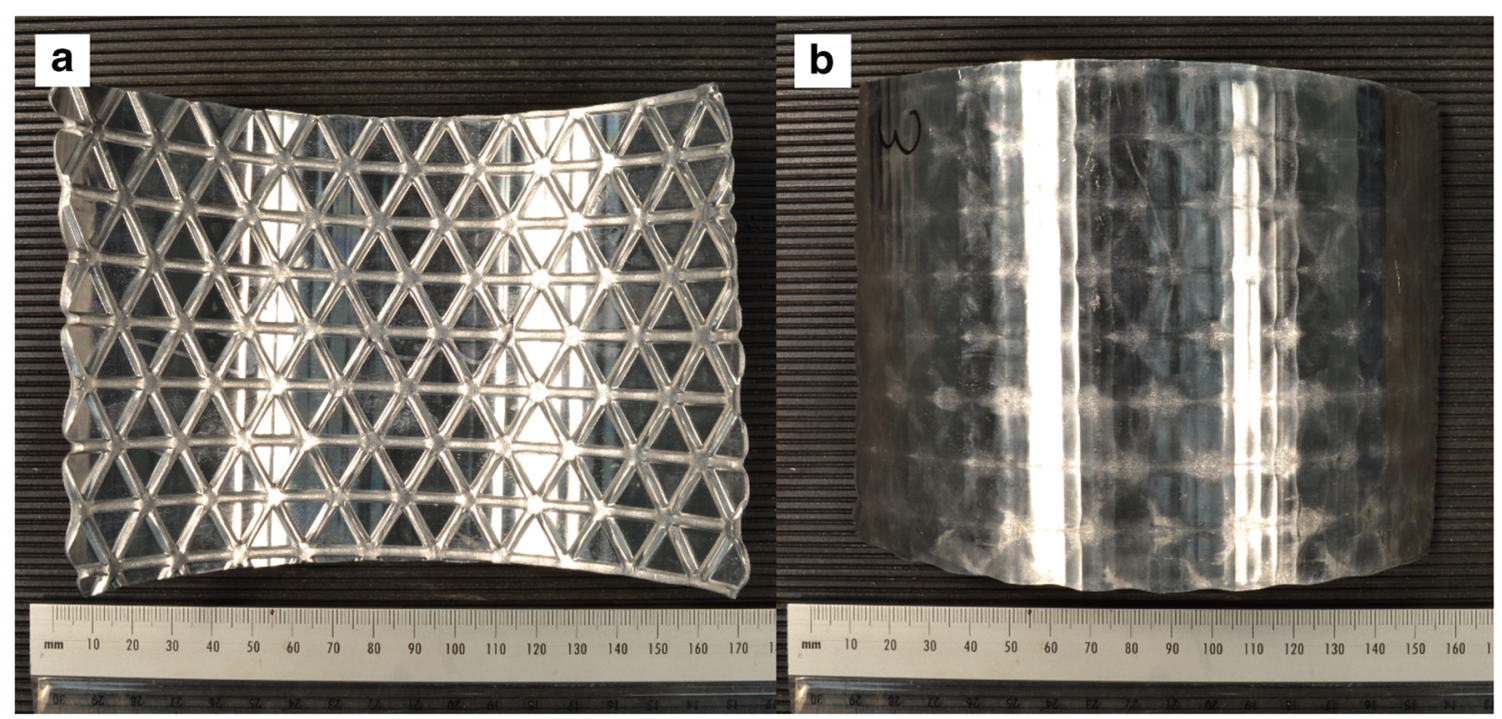

Fig. 7 The ribbed (a) and reverse (b) side of the rolled sample plate

inconsistencies. There was no evidence of cracking in the rolled Isogrid, despite the high elongation of the billet, and large strains imposed to reduce parts of the billet by $52 \%$ of thickness in one pass.

Bending tests were conducted as per Section 2.3 on 4 sample groups: 3 mm AA1050-H14 (as received); 3 mm AA1050$\mathrm{O}$ (annealed at $535^{\circ} \mathrm{C}$ for $1 \mathrm{~h}$ ); rolled Isogrid (ribs up/down, annealed); rolled Isogrid (ribs up/down, as rolled). Figure 10 shows the bending stress curves alongside the nominal ultimate tensile strengths for each temper state of AA1050 [29]. Figure 10 shows that the annealing treatment successfully transformed the samples to the fully annealed - $\mathrm{O}$ condition, and that the cold work imparted during the rolling process transformed the Isogrid into the $-\mathrm{H} 18$ condition or "fully roll-hardened."

Figure 11 shows the specific bending stress as a function of displacement over the course of the bend test for samples with and without an annealing treatment. The specific stress increment, denoted as A in Fig. 11,

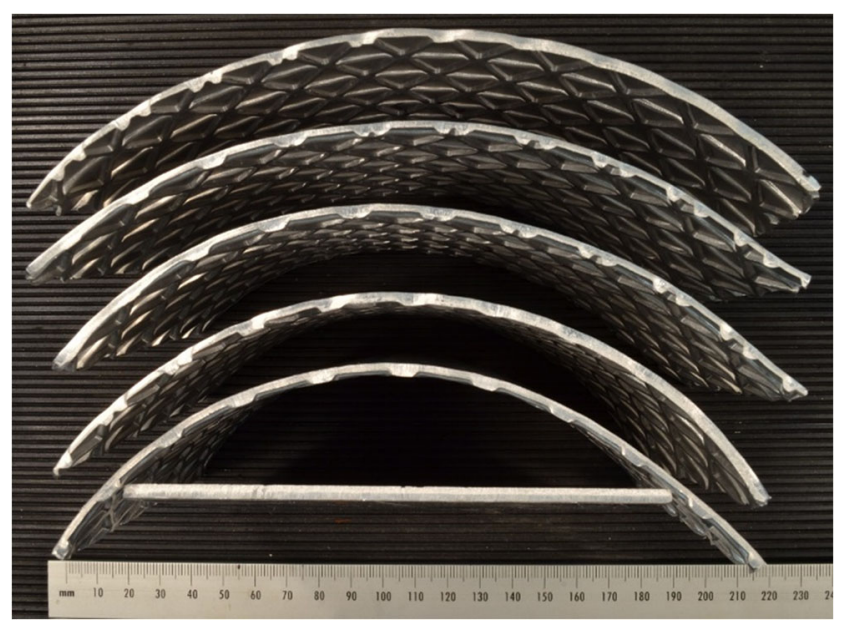

Fig. 8 The rolled sample plates and an initial billet demonstrates that the as-rolled Isogrid is stronger in bending than the as-received plate by $100 \%$. Stress increment B (Fig. 11) shows that the annealed Isogrid is stronger in bending than the annealed plate by $60 \%$. Annealing the samples removed the contribution of cold work to bending strength, revealing only the improvement in strength due to shape factor (see Section 1). Therefore, A denotes the substantial increase in bending strength as a function of the combination of cold work and rib formation in the as-rolled Isogrid, whereas B represents the increase of strength in bending of the produced samples solely attained through the formation of ribs. As the geometry is identical in both sets of data, this suggests that the contribution of shape to the increase in bending strength is $60 \%$ of the overall improvement in the unannealed samples, where cold work accounts for the remaining $40 \%$. The corresponding shape factor for this geometry is the ratio of the maximum bending strengths, which is 1.6 for the annealed samples [6].

The ribs up and ribs down samples exhibited little difference in bending stress (Fig. 12). The jagged profile in the graph following 20-mm displacement is where the "ribs down" specimens were catching on the cylindrical supports. However, the general trends of both data sets are very similar, which provides an indication that the rolled Isogrid is quasiisotropic as bending strength is symmetrical around its neutral axis despite the asymmetrical geometry of the Isogrid itself. Meyer was clear that this is a key feature of Isogrid [10], although it is important to stress that Isogrid does not fail in an isotropic manner as reported by Huybrechts and Tsai [15]. This indicates that Isogrid was successfully rolled (Figs. 10, 11 and 12), as the specimens exhibited a substantial increase in bending stiffness, as described by Meyer [10], while maintaining quasi-isotropic mechanical properties despite their newly formed ribs. 
Fig. 9 A perspective close up of the rolled Isogrid showing the variability in rolled ribs, showing A increased rib height and $\mathrm{B}$ rounding of the rib edge

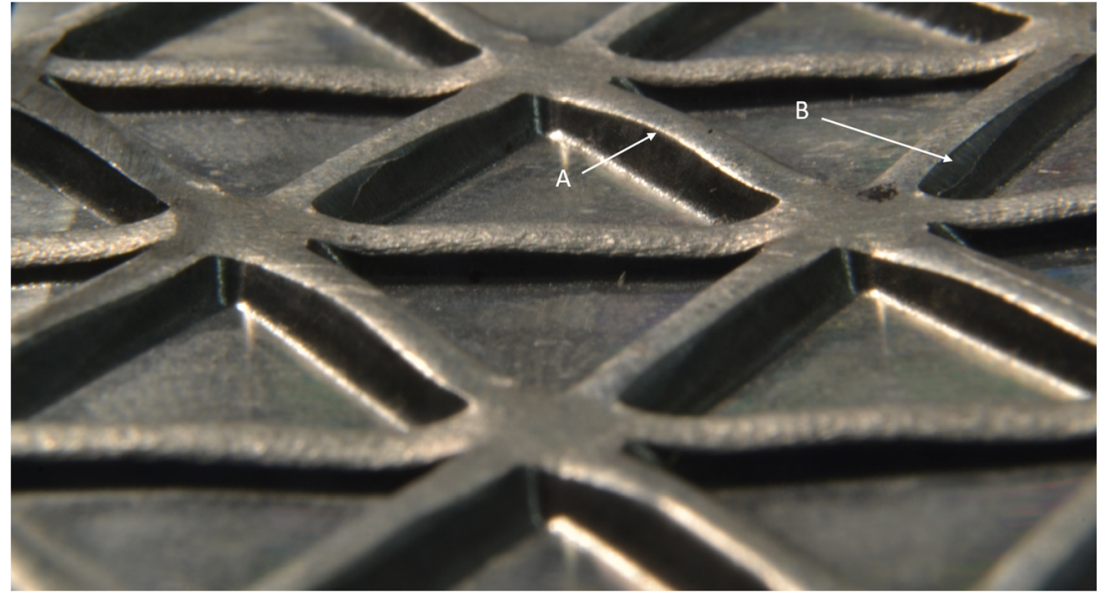

The discussion in Huybrechts and Meink established that aluminium is less popular as a base material for advanced grid-stiffened structures because it is heavy in comparison to modern composite alternatives and production methods for both materials are expensive [19]. However, it can be seen that the method detailed in this article would substantially reduce the cost of aluminium-based Isogrid and other aluminium grid-stiffened structures.

\section{Conclusions}

This study has demonstrated that Isogrid can be rolled and that the design approach to creating a patterned roller to manufacture Isogrid was successful. The Isogrid created using this novel manufacturing process had the key geometrical features of Isogrid without major flaws such as cracks and showed a significant improvement in mechanical properties which were symmetrical around the neutral axis in bending, despite the highly asymmetrical nature of the rolling process. From this study, it is evident that the selected Isogrid geometry is capable of further optimisation to maximise mechanical properties and minimise mass; however, the approach detailed in this paper to designing a corresponding roller is valid.

The rolled samples outperformed the initial 3-mm sheet in terms of bending strength as received; even after removing the contribution of cold work, the rolled samples outperformed the flat samples. This indicates that there is an improvement in strength due to the new geometry and not due to work hardening alone. This improvement can be summarised as follows:

- Bend testing showed an improved bending strength of $100 \%$ in the rolled Isogrid compared to the as-received plate. This is a combination of improvement in shape factor in addition to the beneficial effects of cold work.
Fig. 10 Bending stress against displacement during 3-point bending test, showing approximate temper states of the tested samples

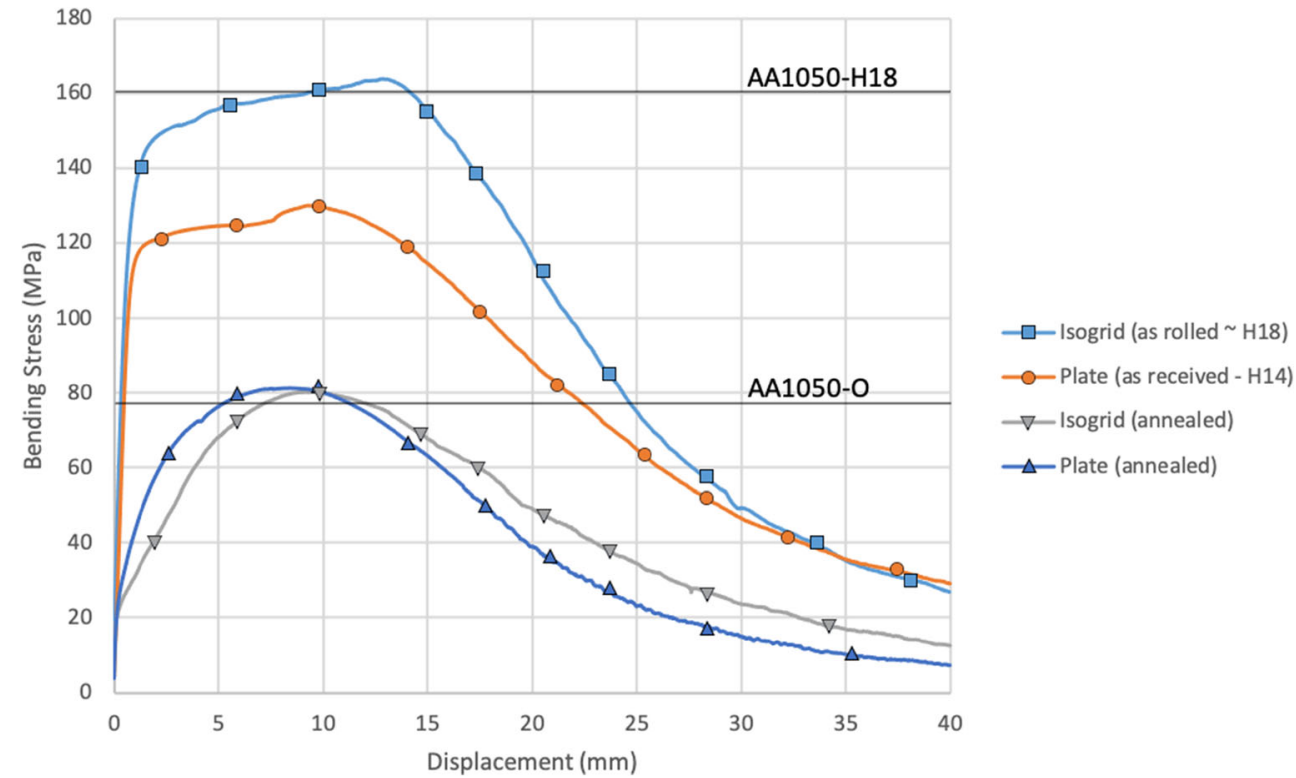


Fig. 11 Specific bending stress against displacement during 3point bending test

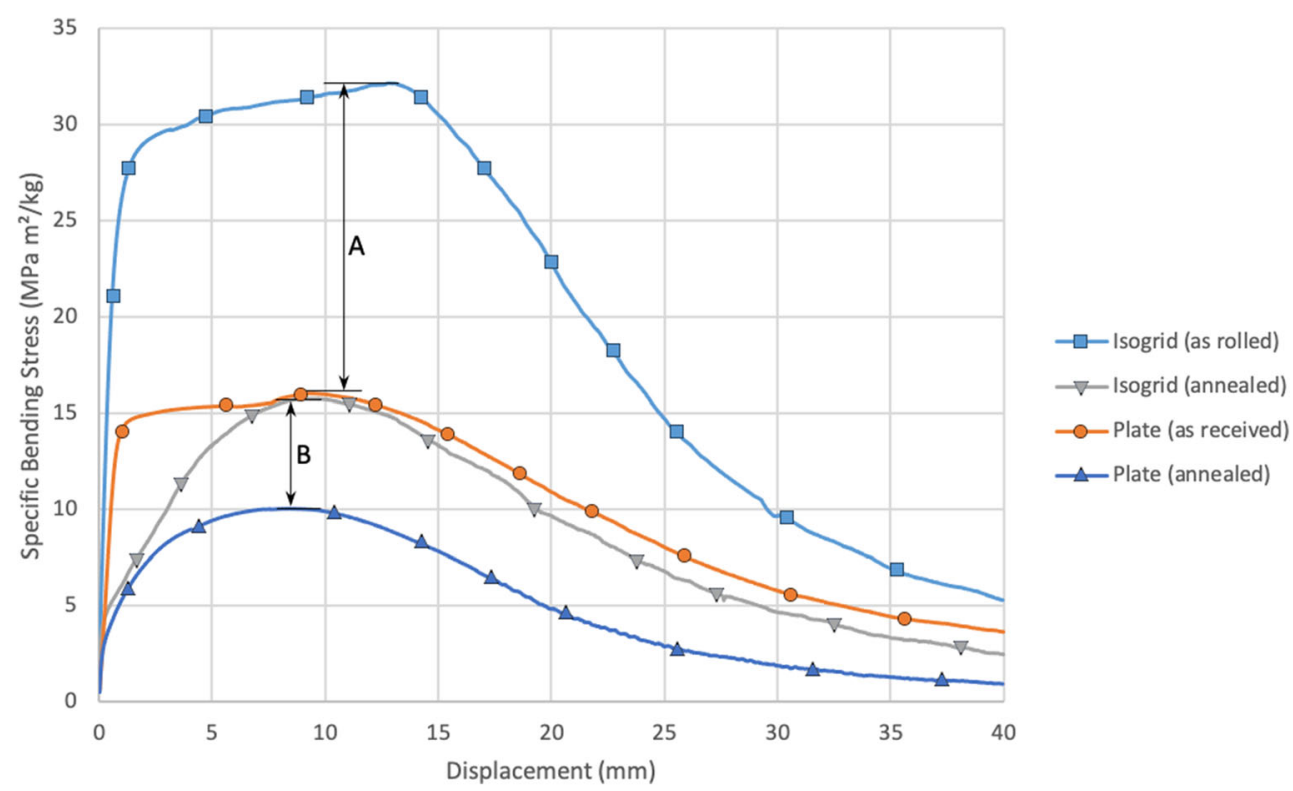

- The cold work imparted during the rolling process transformed the temper state of the Isogrid samples to approximately $-\mathrm{H} 18$, or fully hardened.

- The overall increase in specific bending strength can be decomposed to a contribution of $60 \%$ from shape factor and $40 \%$ from cold work.

- Rolled and annealed Isogrid showed a specific bending strength improvement of $60 \%$ in comparison to annealed plate. This reflects the improvement in strength to mass ratio due to shape alone and can be expressed as a shape factor of 1.6.

These findings demonstrate the significant potential of rolling as a strong contender in the future manufacture of grid-stiffened, lightweight sheet materials such as Isogrid, and that the cost of such structures could be substantially reduced by its adoption.

Acknowledgements The authors wish to acknowledge support from Ocean Kinetics Ltd., Lerwick and the Advanced Materials Research Laboratory, University of Strathclyde.

Authors' contributions All authors contributed equally to the generation and analysis of experimental data, and the development of the manuscript.

Funding This work was funded by the University of Strathclyde and the Advanced Materials Research Laboratory (AMRL).
Fig. 12 Bending stress against displacement during 3-point bending test-Isogrid samples (ribs up and ribs down)

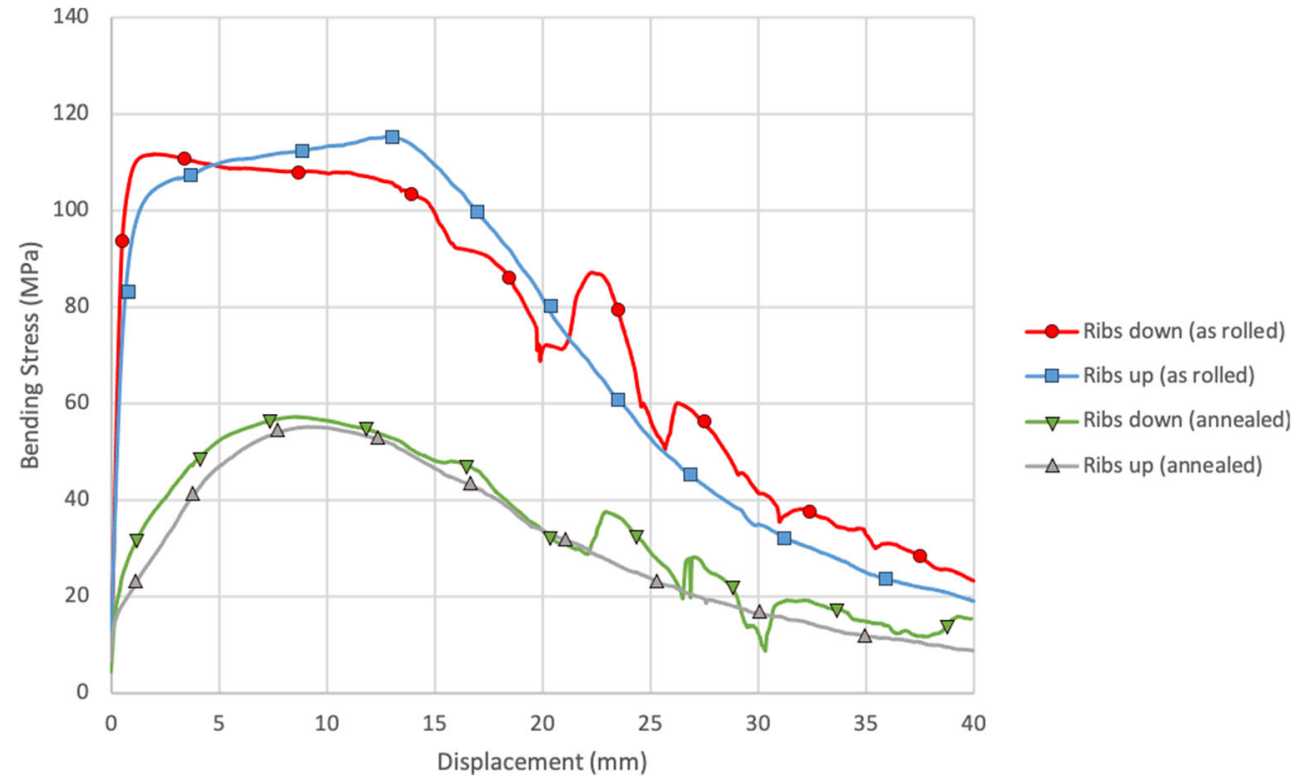




\section{Compliance with ethical standards}

Conflicts of interest The authors declare that they have no conflict of interest.

Open Access This article is licensed under a Creative Commons Attribution 4.0 International License, which permits use, sharing, adaptation, distribution and reproduction in any medium or format, as long as you give appropriate credit to the original author(s) and the source, provide a link to the Creative Commons licence, and indicate if changes were made. The images or other third party material in this article are included in the article's Creative Commons licence, unless indicated otherwise in a credit line to the material. If material is not included in the article's Creative Commons licence and your intended use is not permitted by statutory regulation or exceeds the permitted use, you will need to obtain permission directly from the copyright holder. To view a copy of this licence, visit http://creativecommons.org/licenses/by/4.0/.

\section{References}

1. Evans AG (2001) Lightweight materials and structures. MRS Bull 26:790-797. https://doi.org/10.1557/mrs2001.206

2. Merklein M, Geiger M (2002) New materials and production technologies for innovative lightweight constructions. J Mater Process Technol 125-126:532-536. https://doi.org/10.1016/S09240136(02)00312-6

3. Ashby M (2013) Designing architectured materials. Scr Mater 68: 4-7. https://doi.org/10.1016/j.scriptamat.2012.04.033

4. Bréchet YJM (2013) Chapter 1. Architectured materials: an alternative to microstructure control for structural materials design? A possible playground for bio-inspiration?:1-16. https://doi.org/10. 1039/9781849737555-00001

5. Estrin Y, Beygelzimer Y, Kulagin R (2019) Design of architectured materials based on mechanically driven structural and compositional patterning. Adv Eng Mater 21:1-12. https://doi.org/10.1002/ adem. 201900487

6. Ashby MF (1991) Overview no. 92: materials and shape. Acta Metall Mater 39:1025-1039. https://doi.org/10.1016/09567151(91)90189-8

7. Carruth MA, Allwood JM (2012) The development of a hot rolling process for variable cross-section I-beams. J Mater Process Technol 212:1640-1653. https://doi.org/10.1016/j.jmatprotec.2012.03.006

8. Slysh P, Dyer JE, Furman JH, Key JE (1975) Isogrid structures. AIAA/ASME/SAE 16th Struct Struct Dyn Mater Conf. https://doi. org/10.2514/6.1975-816

9. Meyer RR, March V (1973) Isogrid - a simple, efficient, stiffening concept. NASA. https://doi.org/10.2514/6.1973-365

10. Meyer RR, Harwood OP, Harmon MB, Orlando JI (1973) Isogrid design handbook. NASA

11. Slysh P (1990) Picking the best high-strength, lightweight structures. Mach Des 62:85-89

12. Munroe J, Wilkins K, Gruber M, Domack MS (2000) Integral Airframe Structures (IAS): validated feasibility study of integrally stiffened metallic fuselage panels for reducing manufacturing costs. Tech Rep NASA/CR-2000-209337

13. Pettit RG, Wang JJ, Toh C (2000) Validated feasibility study of integrally stiffened metallic fuselage panels for reducing manufacturing costs. Cost Assessment of Manufacturing/Design Concepts. Tech Rep NASA/CR-2000-209342

14. Wagner J, Domack M, Tayon W, Bird RK (2017) Innovative manufacturing of launch vehicle structures - integrally stiffened cylinder process. NASA

15. Huybrechts S, Tsai SW (1996) Analysis and behavior of grid structures. Compos Sci Technol 56:1001-1015. https://doi.org/10.1016/ 0266-3538(96)00063-2

16. Slysh P Image of isogrid being milled. Isogrid SST Website 2014. Retrieved on 10 Sept 2020 from https://web.archive.org/web/ 20160405190612/http://isogrid-sst.com/MachineDesign5.JPG

17. Slysh P, Ringwald RS, Dyer JE, Browing DL 1063. Isogrid weight optimum structures. 34th Annu Conf Seattle, Washington, May 5-7 1975

18. Lam ACL, Shi Z, Yang H, Wan L, Davies CM, Lin J, Zhou S (2015) Creep-age forming AA2219 plates with different stiffener designs and pre-form age conditions: experimental and finite element studies. J Mater Process Technol 219:155-163. https://doi. org/10.1016/j.jmatprotec.2014.12.012

19. Huybrechts S, Meink TE (1997) Advanced grid stiffened structures for the next generation of launch vehicles. IEEE Aerosp Appl Conf Proc 1:263-269. https://doi.org/10.1109/aero.1997.574417

20. Ivanco ML, Domack MS, Stoner MC, Hehir AR (2016) Costbenefit analysis for the advanced near net shape technology (ANNST) method for fabricating stiffened cylinders. AIAA Sp Astronaut Forum Expo Sp 2016:1-19. https://doi.org/10.2514/6. 2016-5488

21. Gau JT, Principe C, Wang J (2007) An experimental study on size effects on flow stress and formability of aluminm and brass for microforming. J Mater Process Technol 184:42-46. https://doi. org/10.1016/j.jmatprotec.2006.11.003

22. Gutscher G, Wu HC, Ngaile G, Altan T (2004) Determination of flow stress for sheet metal forming using the viscous pressure bulge (VPB) test. J Mater Process Technol 146:1-7. https://doi.org/10. 1016/S0924-0136(03)00838-0

23. Sabroff AM, Boulger FW, Henning HJ, Spretnak JW (1964) A manual on fundamentals of forging practice

24. Malinowski Z, Pietrzyk M, Lenard JG (1993) Analysis of the flatrolling process: one-dimensional and finite-element models. J Mater Process Technol 39:373-387. https://doi.org/10.1016/09240136(93)90170-B

25. Lenard JG (2007) Primer on flat rolling. https://doi.org/10.1016/ B978-0-08-045319-4.X5000-1

26. Hacquin A, Montmitonnet P, Guillerault JP (1994) Experimental validation of a rolling stand elastic deformation model. J Mater Process Technol 45:199-206. https://doi.org/10.1016/09240136(94)90341-7

27. British Standards Institution. BS EN ISO 74382016

28. Pośpiech J (1987) A note on the influence of some factors affecting curvature in the flat rolling of strip. J Mech Work Technol 15:69 80. https://doi.org/10.1016/0378-3804(87)90007-6

29. ASM International (1990) Properties of wrought aluminum and aluminum alloys. Prop. Sel. Nonferrous Alloy. Spec. Mater, vol 2, 10th edn. ASM International, pp 62-122. https://doi.org/10. 31399/asm.hb.v02.a0001060

Publisher's note Springer Nature remains neutral with regard to jurisdictional claims in published maps and institutional affiliations. 